\title{
Airborne Radioactivity in Hot Lab of Nuclear Medicine
}

\author{
J. Ferdous $^{1^{*}}$ N. Sharmin ${ }^{2}$, A. Begum ${ }^{1}$, A. Begum ${ }^{2}$ \\ ${ }^{1}$ Health Physics division, Atomic Energy Centre, Dhaka-1000, Bangladesh \\ ${ }^{2}$ Department of Physics, University of Dhaka, Dhaka-1000, Bangladesh
}

Received 5 October 2016, accepted in final revised form 2 April 2017

\begin{abstract}
In this study, identification and measurement of gamma emitting radionuclides contaminant in air inside the hot lab at the Institute of Nuclear Medicine have been carried out. Air particulate collection has been performed by suction of indoor air through filter paper using Staplex air sampler. The radioactivities of Pb-212, Pb-214, Ac-228, Bi-214, K-40, I-131 and Tc-99m captured by the filter paper were assessed using gamma-ray spectrometry. The observed activities of natural radionuclides in air samples ranged from 0.59 to $295 \mathrm{mBq} / \mathrm{m}^{3}$ with average $143 \pm 0.003 \mathrm{mBq} / \mathrm{m}^{3}$ for $\mathrm{Pb}-212 ; 13.55$ to $1911 \mathrm{mBq} / \mathrm{m}^{3}$ with average $402 \pm 0.007 \mathrm{mBq} / \mathrm{m}^{3}$ for $\mathrm{Pb}-214 ; 0.69 \mathrm{mBq} / \mathrm{m}^{3}$ to $571 \mathrm{mBq} / \mathrm{m}^{3}$ with average $57.33 \pm 0.009$ $\mathrm{mBq} / \mathrm{m}^{3}$ for Ac-228; 7.85 to $2192 \mathrm{mBq} / \mathrm{m}^{3}$ with average $543 \pm 0.014 \mathrm{mBq} / \mathrm{m}^{3}$ for Bi-214 and from $9.89 \mathrm{mBq} / \mathrm{m}^{3}$ to $256 \mathrm{mBq} / \mathrm{m}^{3}$ with average $92.9 \pm 0.052 \mathrm{mBq} / \mathrm{m}^{3}$ for $\mathrm{K}-40$. The activities of artificial radionuclides in air filter ranged from 0.19 to $60.67 \mathrm{mBq} / \mathrm{m}^{3}$ with average $6.4 \pm 0.0 \mathrm{mBq} / \mathrm{m}^{3}$ for I- $131 ; 0.25$ to $40.27 \mathrm{mBq} / \mathrm{m}^{3}$ with average $4.17 \pm 0.0 \mathrm{mBq} / \mathrm{m}^{3}$ for Tc-99m. The activity of I-131 is compared with the reported values of other countries of the world. This demonstrated that the work place condition is satisfactory and the level of protection provided to the worker is sufficient.
\end{abstract}

Keywords: Gamma-ray spectrometry; Air filter; $\gamma$-Emitting radionuclides; Activity and nuclear medicine.

(C) 2017 JSR Publications. ISSN: 2070-0237 (Print); 2070-0245 (Online). All rights reserved. doi: http://dx.doi.org/10.3329/jsr.v9i2.29873 J. Sci. Res. 9 (2), 159-166 (2017)

\section{Introduction}

Radioactivity is an omnipresent phenomenon in the environment, and naturally occurring radionuclides have always been present in our surroundings. One can distinguish between three different origins of natural radionuclides: primordial, decay products and cosmogenic. Primordial cosmogenic or anthropogenic radionuclides present in the ambient air are useful tracers for studying physical and health-related processes in the atmosphere [1]. Primordial radionuclides, like e.g. ${ }^{40} \mathrm{~K}$, have very long half-lives $(\sim 105-$ 109 years) and have been present in the crust of the Earth since its creation. Decay

\footnotetext{
*Corresponding author: ferdous28@yahoo.com
} 
products are part of one of the three natural decay chains: the uranium, thorium, and actinide series. The assessment of gamma radiation doses from natural sources is of particular importance because natural radiation is the largest contributor of external dose to the world population. Knowledge of the concentrations and distributions of the radionuclides in air particles are of interest since they provide useful information on the monitoring of environmental contamination by radioactive materials in the natural environment [2]. Nuclear medicine is an important and specialized branch of medical practice. It uses radio-nuclides, for diagnosis and treatment of diseases. The practice causes ionizing radiation exposures to the occupational worker, patient and public. The radiation exposure carries health risks for the exposed persons and also pollutes the environment. Continuous monitoring of environment, workers, patients, public and provide guidance for the safe design, installation and operation to the nuclear medicine center/hospitals/institute is mandatory to strengthen radiation protection. Background radiation is the radiation constantly present in the natural environment of the Earth, which is emitted by natural and artificial sources. Natural radioactivity is wide spread in the earth's environment; it exists in soil, plants, water and air. Exposure of radiation mainly comes from natural radiation $(85 \%)$ [3].

Tc $-99 \mathrm{~m}$ generator to fulfill the nuclear medicine demand locally .The excited state of Tc-99m with $6 \mathrm{~h}$ half-life gives researchers enough time to use this isotope. Technetium$99 \mathrm{~m}$ is employed in about $80 \%$ of all nuclear medicine procedures. This is because it has almost ideal characteristics for a nuclear medicine scan. In order to eventually leave the excited state, the nuclei of Tc-99m emit gamma rays with a characteristic energy of 140 $\mathrm{keV}$. This property makes them highly desirable in medical application, as gamma rays are absorbed far from the examined organ, minimizing the danger posed to living matter. Iodine-131 has a convenient half-life and energy characteristics $\left(\mathrm{T}_{1 / 2}=8.1\right.$ days). I-131 is used for both diagnostic and therapeutic purposes. Such as, diagnostic studies of thyroid disorders, therapeutic application for treatment of thyrotoxicosis and thyroid cancer Sodium iodide in liquid form is highly volatile and needs special handling in a fume hood with exhaust system to avoid inhalation of the iodide vapor during labeling. It also means that personnel handling the radiopharmaceutical should be subjected to periodic assays to exclude uptake in their thyroid glands. However, I-131 remains the most commonly used therapy radionuclide in nuclear medicine. When used for treating non-thyroid malignancies, unwanted uptake of I-131 in normal thyroid gland needs to be blocked by administering elemental iodide, in the form of Lugol's iodine or strong solution of Potassium Iodide (SSKI) [4].

The assessment of gamma radiation doses from natural sources is importance because natural radiation is the largest contributor of external dose to the world population. Throughout the history of life on earth, organisms have been continuously exposed to radiations from radio-nuclides produced by cosmic ray interaction in the atmosphere and radiations from naturally occurring substances that are spatially distributed in all living and non-living components of the biosphere [3]. There are 18 Nuclear Medicine Centers in Bangladesh, from these Centers only one is selected for this study: National Institute of 
Nuclear Medicine and Allied Science (NINMAS) Dhaka. While processing and labeling of the liquid sources with labeling compounds, the sources may enter the bodies of the occupational worker through inhalation and ingestion [5]. The purpose of the present study has been to assess the activity of natural and artificial radionuclides in the air from the hot lab of the Institute of Nuclear Medicine (INM) concerning the human health and environment hazard due to airborne radioisotopes.

\section{Experimental}

\subsection{Sample collection and preparation}

Air samples were collected from the hot laboratory, radioiodine treatment rooms of Institute of Nuclear Medicine (INM). From 7 January 2012 to 15 May 2013, total 35 air samples were taken on random basis. Air particulate collection was performed by suction of indoor air through filter paper using portable Staplex air sampler. Before collecting air particulates on filter paper, air filter weight was measured. The flow rate of the Staplex air sampler was $30 \mathrm{ft}^{3} / \mathrm{min}$ and the sampler run for $60 \mathrm{~min}$. At the end of sampling, the filter was packed in plastic bags as 'packet sample' and measurement geometry used for gamma-ray spectrometry.

\subsection{Measurement procedure}

The radioactivity measurement was performed by a high-resolution gamma spectroscopic system employing a high purity germanium crystal (HPGe) coupled with multichannel analyzer. This detector was a p-type co-axial detector and low background to determine gamma-ray emitters. The effective volume of the detector was $83.46 \mathrm{~cm}^{3}$ and energy resolution of the $1.33 \mathrm{MeV}$ energy peak for ${ }^{60} \mathrm{Co}$ was found as $1.69 \mathrm{keV}$ at full width half maximum (FWHM) with a relative efficiency of $19.6 \%$. The gamma-ray spectrum of each individual sample was recorded using a PC based 4096 channel analyzer and processed by Silena Emca plus software. The bias voltage of the detector was +3200 volts. In order to reduce the thermally generated charge carrier to an acceptable level, the detector was cooled by liquid nitrogen of $77 \mathrm{~K}$, which was the common cooling medium of the detector. To minimize the effect of the scattered radiation from the shield, the detector was located at the center of the chamber. The detector was calibrated using gamma-ray standard point sources. The detector was shielded by $10 \mathrm{~cm}$ lead on all sides with $2 \mathrm{~mm}$ copper in inner sides and lead shielding covered by lead bricks at the top to reduce background radiation effects. The characteristic gamma peaks selected for the determination of natural artificial radionuclides were $238 \mathrm{keV}$ for the $\mathrm{Pb}-212,295 \mathrm{keV}$ and $352 \mathrm{keV}$ for the Pb-214, $609 \mathrm{keV}$ for the Bi-214, $911 \mathrm{keV}$ for the Ac-228, $1461 \mathrm{keV}$ for the K-40 and $364 \mathrm{keV}$ for I-131, $140 \mathrm{keV}$ for Tc-99m. The counting time for each filter paper was $5000 \mathrm{sec}$. Gamma ray spectrum of an air filter sample has been shown in Fig. 1. The background spectra were measured frequently under the same conditions in order to correct the calculated sample activities. 


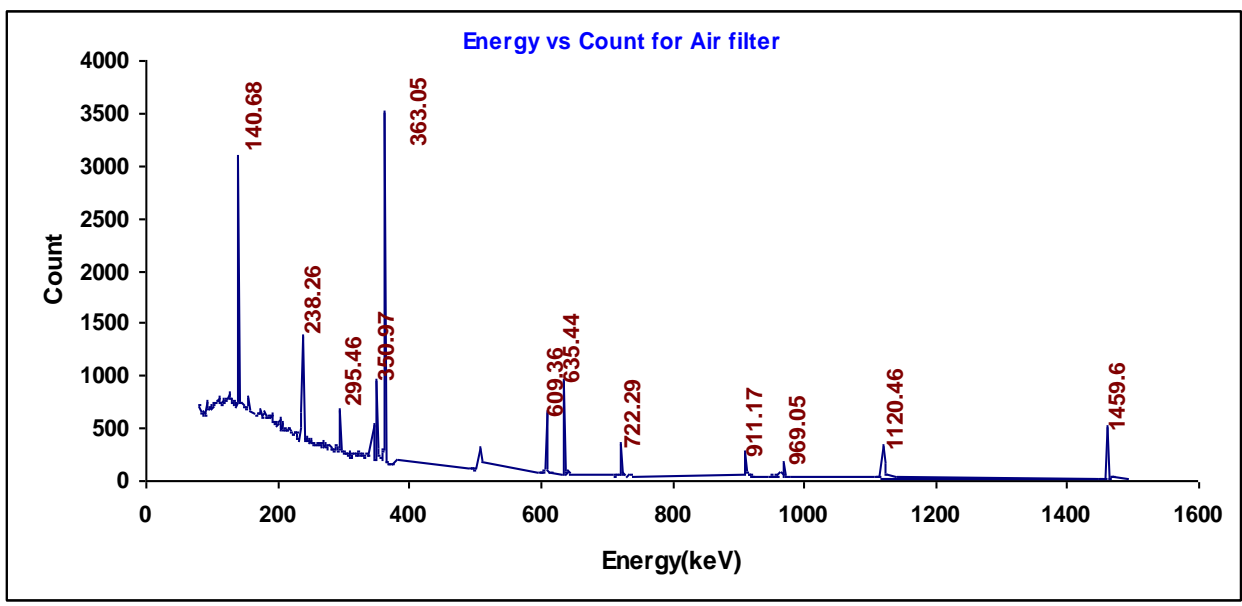

Fig. 1. Gamma spectrum of an Air filter.

In order to perform the quality control for making relevant samples, a sample with a defined activity was analyzed using the generated efficiency curve.

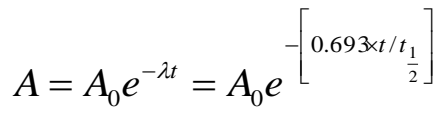

Where, $\mathrm{A}_{0}=$ the initial activity of the reference sources

$\mathrm{A}=$ activity of that reference source on the measurement date

$\lambda=$ the decay constant of the source

$\mathrm{t}=$ the elapsed time

$t_{1 / 2}=$ half-life of the radioactive source

The efficiency calibration curve was made using different energy peaks covering the range from $60 \mathrm{keV}$ to $2000 \mathrm{keV}$ to obtain the efficiency of the detector for the particular gamma ray energy of interest. The efficiency of the HPGe detector for a particular reference source of particular gamma ray energy can be found from the following equation [6].

$$
\varepsilon=\left(N(c p s) /\left(p_{\gamma} \times A_{r e f}\right)\right) \times 100 \%
$$

Where, $\varepsilon=$ efficiency; $\mathrm{N}(\mathrm{cps})=$ net count per second

$\mathrm{p}_{\gamma}=$ the fraction of a particular gamma-ray energy and

$\mathrm{A}_{\text {ref }}=$ activity of that reference source on the measurement date. 
The calculation of the concentration of different radionuclides was based on the measured detector efficiency as a function of energy as in Fig. 2 for the same counting geometry and time.

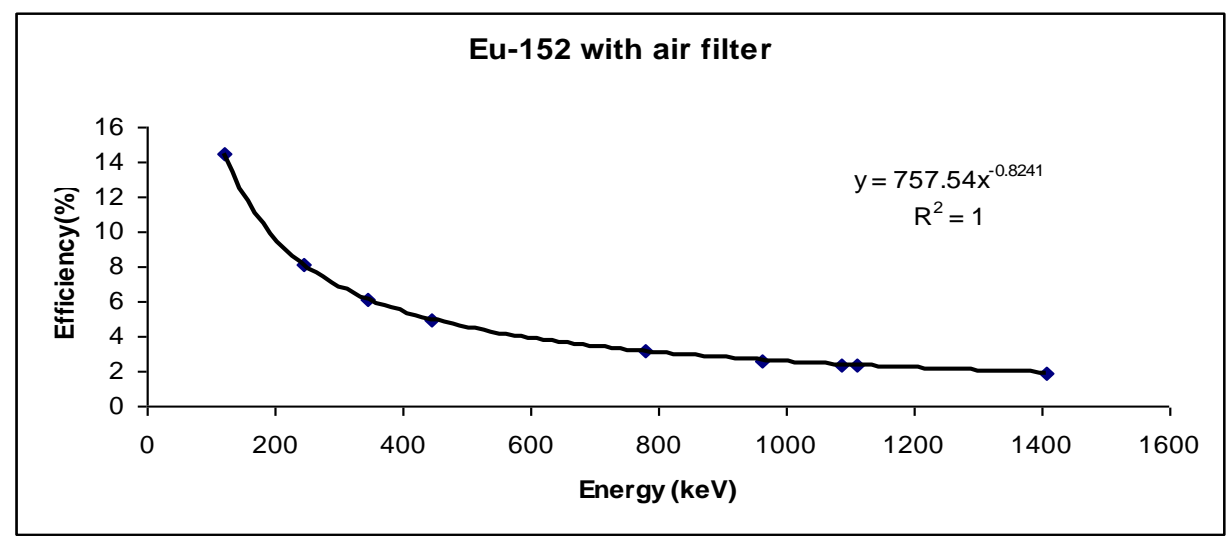

Fig.2. Energy vs Efficiency curve.

\subsection{Activity calculation}

Since the detection system gives only the count rate which was proportional to the amount of radioactivity in the samples, the radioactivity concentration in air samples was obtained as follow:

$$
A=(\text { Netcps }) /\left(p_{\gamma} \times \varepsilon \times 50.97\right) \quad\left(\mathrm{Bq} / \mathrm{m}^{3}\right)
$$

Where, $A$ is activity of the radionuclide in $\mathrm{Bq} / \mathrm{m}^{3}$ present in the samples; Net cps is Net count per second; $P_{\gamma}$ is the fraction of a particular gamma-ray energy; $\varepsilon$ is efficiency of the detector for a particular gamma-ray energy and $50.97 \mathrm{~m}^{3}=$ total flow of air in one $\mathrm{h}$.

In the present study standard characteristics values of $P_{\gamma}$ were used from technical reports series no. 295, 1989. The activity of the sample was given in $\mathrm{mBq} / \mathrm{m}^{3}$ and the measurement errors shown in Table 1 represent one-sigma uncertainties. The error calculation was done by the following formula [6]:

$$
\sigma=\sqrt[2]{\left[S+B / T^{2}+B / T^{2}\right]}
$$

Where, $S+B$ is total sample with background counts; $B$ is total background counts; $T$ is time in seconds. 
The error activity was done by the following formula:

Error Activity $=(\sigma) /\left(p_{\gamma} \times \varepsilon \times 50.97\right) \quad\left(\mathrm{Bq} / \mathrm{m}^{3}\right)$

Where, $\sigma$ is error Count; $p_{\gamma}$ is the fraction of a particular gamma-ray energy; $\varepsilon$ is efficiency of the detector for a particular gamma-ray energy and $50.97 \mathrm{~m}^{3}=$ total flow of air in one h.

\section{Results and Discussion}

The natural and artificial radionuclides identified and their corresponding maximum, minimum and average activities in air samples at hot laboratory of INM have been presented in Table 1.

Table 1. Radioactivity in air sample at Hot lab in INM.

\begin{tabular}{llll}
\hline Radionuclide & $\begin{array}{l}\text { Maximum activity } \\
\text { in } \mathrm{mBq} / \mathrm{m}^{3}\end{array}$ & $\begin{array}{l}\text { Minimum activity } \\
\text { in } \mathrm{mBq} / \mathrm{m}^{3}\end{array}$ & $\begin{array}{l}\text { Average activity } \\
\text { in } \mathrm{mBq} / \mathrm{m}^{3}\end{array}$ \\
\hline $\mathrm{Pb}-212$ & 295 & 0.59 & 143 \\
$\mathrm{~Pb}-214$ & 1911 & 13.55 & 402 \\
$\mathrm{Ac}-228$ & 571 & 0.69 & 57.33 \\
$\mathrm{Bi}-214$ & 2192 & 7.85 & 543 \\
$\mathrm{~K}-40$ & 256 & 9.89 & 92.9 \\
$\mathrm{I}-131$ & 60.67 & 0.19 & 6.4 \\
$\mathrm{Tc}-99 \mathrm{~m}$ & 40.27 & 0.25 & 4.17 \\
\hline
\end{tabular}

The radioactivity ranged from 0.59 to $295 \mathrm{mBq} / \mathrm{m}^{3}$ for $\mathrm{Pb}-212$ with mean value $143 \pm 0.003 \mathrm{mBq} / \mathrm{m}^{3}$. It is a radioactive radon isotope which can escape from the building materials and ascend into the air. The presence of $\mathrm{Pb}-212$ in atmospheric dust particles and virtually all other types of geological materials and even in radiation shielding materials and cement flooring are the most probable reason of finding activity in air of hot lab of INM. The radioactivity ranges from 13.55 to $1911 \mathrm{mBq} / \mathrm{m}^{3}$ for $\mathrm{Pb}-214$ with mean value $402 \pm 0.007 \mathrm{mBq} / \mathrm{m}^{3}$. Pb-214 can attach to dust and other particles in air sample. The radioactivity ranges from 0.69 to $571 \mathrm{mBq} / \mathrm{m}^{3}$ for Ac-228 with mean value $57.33 \pm 0.009$ $\mathrm{mBq} / \mathrm{m}^{3}$. The radioactivity ranges from 7.85 to $2192 \mathrm{mBq} / \mathrm{m}^{3}$ for $\mathrm{Bi}-214$ with mean value $543 \pm 0.014 \mathrm{mBq} / \mathrm{m}^{3}$. The radioactivity ranges from 9.89 to $256 \mathrm{mBq} / \mathrm{m}^{3}$ for K-40 with mean value $92.9 \pm 0.052 \mathrm{mBq} / \mathrm{m}^{3}$. Potassium- $40(\mathrm{~K}-40)$ is a naturally-occurring radionuclide. Building and tilling materials used in the house construction may contain $\mathrm{K}$ 40.

The radioactivity ranged from 0.19 to $60.67 \mathrm{mBq} / \mathrm{m}^{3}$ for $\mathrm{I}-131$ and the mean value is $6.4 \pm 0.0 \mathrm{mBq} / \mathrm{m}^{3}$. When I-131 was mixed with non-radioactive solution it mixed up with the air for its volatile nature. As the half-life of I-131 is quite long it was found in the air almost every day of the week at INM whether it is used or not on a particular day. The maximum activity of I-131 found in air was $60.67 \mathrm{mBq} / \mathrm{m}^{3}$ when vial containing $116 \mathrm{mCi}$ 
of I-131 was opened in the laboratory. The minimum activity of I-131 was $0.19 \pm 0.0$ $\mathrm{mBq} / \mathrm{m}^{3}$ when vial containing $157.6 \mu \mathrm{Ci}$ of $1-131$ was opened in the laboratory. The radioactivity ranges from 0.25 to $40.27 \mathrm{mBq} / \mathrm{m}^{3}$ for Tc- $99 \mathrm{~m}$ and mean value is $4.17 \pm 0.0$ $\mathrm{mBq} / \mathrm{m}^{3}$. The maximum activity found in air was $40.27 \mathrm{mBq} / \mathrm{m}^{3}$ when vial containing 596 $\mathrm{mCi}$ of Tc-99m was opened in the laboratory. The minimum activity of Tc-99m was 0.25 $\mathrm{mBq} / \mathrm{m}^{3}$ when vial containing $99 \mathrm{mCi}$ of Tc-99m was opened in the laboratory.

As artificial radionuclide I-131 was used for both diagnostic and therapeutic purposes at INM. The highest concentration up to $60.67 \mathrm{mBq} / \mathrm{m}^{3}$ has been detected at the fume hood area where the I-131 treatment dose was dispensing. Jaminez et al. reported higher concentration of $\mathrm{I}-131$, between 0.037 to $0.50 \mathrm{~Bq} / \mathrm{m}^{3}$ while preparing and administering I-131 treatment dose ranged from $0.555 \mathrm{GBq}(15 \mathrm{mCi})$ to $7.4 \mathrm{GBq}(200 \mathrm{mCi})$. Bright et al. [7] demonstrated that the amount of I-131, which volatilized daily from the exposed therapy capsules, was only in a small percentage of the capsule activity when compared to the amount of volatile I-131 while dispensing and injecting I-131 solution in to the capsule. The air concentration of I-131 as high as 80 to $400 \mathrm{~Bq} / \mathrm{m}^{3}$ in isolated room has been reported by Ibis et. al [8]. This study established that airborne I-131 released into the general environment of nuclear medicine workplaces were well below the above reported values. The inhalation of radioiodine vapors is the important routes of entry of radioiodine into the human body. The level of airborne I-131 radioactivity should be maintained well below allowable levels to keep the internal dose equivalent contribution to the total effective dose equivalent small.

\section{Conclusion}

In this study, the activity of natural and artificial radionuclides in the air sample inside the hot lab of the Institute of Nuclear Medicine (INM) has been presented. Especially, large amounts of unsealed radioactive sources (such as I-131 and Tc-99m) are routinely handled in the nuclear medicine laboratory and there is a possibility of exposure to the user (technician, scientists, physicist, or physician) and contamination the environment. It is important to monitor radiation levels to ensure the safety of the people working in areas, where radiation is present. Results for natural and artificial radionuclides in the air concentration have been measured as part of a workplace-monitoring program. These demonstrated that airborne radionuclides released into the general environment of nuclear medicine workplaces are well below the allowable limits, and could be concluded that the work place condition is satisfactory. The level of protection provided to the worker is sufficient to minimize the internal dose equivalent in compliance with the international standards.

\section{References}

1. H. W. Gaggeler, Radiochim Acta 70/71, 345 (1995). https://doi.org/10.1524/ract.1995.7071.special-issue.345

2. J. Ferdous, M. S. Hossain, and M. A. Hoque, Int. J. Life Sci. Technol. 9(12), 96 (2016). 
3. M. Degerlier and G. Ozger, Radi. Prot. Dosi. 132(3), 350 (2008).

4. J. G. Rajendran, A. K. Gopal, D. R. Fisher, L. D. Durack, T. A. Gooley, and O. W. Press, J. Nucl. Med. 49(5), 837 (2008). https:// doi:10.2967/jnumed.107.043190

5. J. Ferdous, S. Hossain, F. Begum, and M. D. A. Hoque, Int. J. Radio. Radia. Ther. 1(2), 1 (2016). https://doi:10.15406/ijrrt.2016.01.00008

6. G. F. Knoll, Radiation Detection and Measurement, 2nd Edition (John Wiley and Sons Inc. USA, 1989).

7. J. M. Bright, T. T. Rees, L. E. Baca, and R. L. Green, J. Nucl. Med. Technol. 28, 52 (2000).

8. E. Ibis, C. R. Wilson, B. D. Collier, G. Akansel, A. T. Isitman, and R. G. Yoss, J. Nucl. Med. 33, 12 (1992). 